\title{
1. An introduction to women in STEM careers: International perspectives on increasing workforce participation, advancement and leadership
}

\section{Diana Bilimoria, Linley Lord and Melissa Marinelli}

The fields of science, technology, engineering and mathematics (STEM) continually bring innovation and improvement to our daily lives as well as offer the potential for expansion of business and employment. Science and technology are applied to discover new opportunities and solve problems, and shape the formation, design, and development of new products and innovative production processes. An advanced science and technology enterprise offers distinctive national advantages to compete and win in today's fast-paced global business environment. With this increasing importance of science and technology for global economic competitiveness and growth, considerable attention is being paid to these industries as career choices for women and men. Individuals with STEM expertise have become critical for the success of both industry and academe sectors as their talents are conducive to an increased capacity for innovation.

Clearly, the full participation of women and men in STEM workforces is necessary to solidify and grow competitive advantage in the coming years and decades, yielding long-term benefits to national economies. Not surprisingly, in recent years there has been considerable focus in the United States, the United Kingdom, Europe and Australia on increasing the number of women in STEM fields. Over the past 40 years, initiatives implemented and supported by government, industry, academic institutions, and companies have aimed to attract and retain women into these professions (National Academies, 2007; Australian Academy of Science, 2013). Governments have committed considerable resources to attract women into STEM programs and equal opportunity legislation has 
resulted in changes in organizational practice with an aim to improve the workforce participation and advancement to leadership of women in STEM. Concurrently, there has been a spate of research on the lack of women in STEM areas including a number of recommendations for increasing attraction and retention rates (e.g., Bell, 2009; genSet, 2010; National Science Foundation, 2010). Despite this focus, women's participation in science and technology based careers remains disappointingly low in the industrialized world and their progress into senior roles can be best described as slow (Bell, 2009). Indeed, there are suggestions that progress may have stalled (Mills et al., 2010). Much of the previous research has explored the reasons why women leave or fail to succeed long term in STEM careers. Well documented are the lack of a critical mass of women in STEM at all ranks and in leadership, a leaky pipeline (the systematic loss of women at key career transition points), unequal employment opportunities and sex based occupational segregation (e.g., disproportionately large numbers of women in certain STEM fields and disproportionately few in others), inequitable treatment and valuing of women employees (for example, through stereotyping, excessive scrutiny, biased evaluations, and unequal access to resources and compensation), and differential effects of conflicts between work and life/family demands for women and men employees. We believe that it is timely now to focus also on success stories, as they may provide insights and new ways to address the issue at individual and systemic levels.

Thus, the aim of this volume is to bring together current research that spans both industry and academic sectors to examine the reasons for women's low participation in STEM and offer examples of successful ameliorative strategies at individual and systemic (organizational and profession/industry) levels. The research presented in this volume focuses on the barriers that women continue to face in STEM fields, the nature of STEM careers as experienced by women, individual career success strategies, and successful organizational and institutional initiatives related to appreciating, advancing and developing the contributions and careers of women in STEM.

Adopting an international perspective, we draw on research from the United States, Europe and Australia not only to explore the reasons for women's low participation in STEM fields but also to draw attention to the places where progress has occurred. We present the latest research spanning industry and academe, focusing on individual career success stories and successful organizational, institutional and educational initiatives related to women in STEM careers. Our focus in this volume is a shift from previous work, building on and complementing existing 
knowledge that pertains to the barriers and issues that women in these professions continue to face.

\section{WHAT DO WE KNOW ABOUT WOMEN IN STEM CAREERS?}

The dearth of women in STEM professions is a persistent puzzle that intrigues researchers and practitioners alike. This lack is a common phenomenon across the industrialized world (Hewlett et al., 2008; Bell, 2009; genSet, 2010). Those interested in how and why the proportion of women in these professions remains low and unchanging have produced a substantive body of work exploring the attraction, retention and attrition of women in STEM studies, in academia and in professional STEM careers (see for example McIlwee and Robinson, 1992; Burke and Mattis, 2007; National Research Council, 2007; European Parliament, 2008; Hewlett et al., 2008; Mills et al., 2008; Fouad et al., 2011; Fouad and Singh, 2011).

Yet despite increases in the numbers of women obtaining university qualifications in STEM fields including through to doctoral level, women remain underrepresented in the sciences both academically and professionally (Valian, 1998; Bilimoria, Joy and Liang, 2008; Bell, 2009; Bilimoria and Liang, 2012). Issues that have been identified that impact on women's under-representation include the lack of role models; assessment, recruitment and promotion systems that favor men; and underrepresentation that can lead to token status and to excessive commitments in order to meet the organization's gender equity commitments (genSet, 2010). Hostile work environments and extreme job pressures have also been identified as major factors regarding why women leave the sciences (Hewlett et al., 2008). In this regard, Fouad and Singh (2011) found in their survey that nearly half of the 3700 women respondents who had graduated with an engineering degree said they left because of working conditions, too much travel, and lack of advancement or low salary and a third of the women left because they did not like the workplace climate, their boss or the organization's culture.

In academic settings, women are less likely to have doctoral degrees and are more likely to be employed in non-tenure track positions (Long, 2001; Bilimoria and Liang, 2012). Goulden, Frasch and Mason (2009) found that family formation - most importantly marriage and childbirth accounts for the largest leaks in the pipeline between $\mathrm{PhD}$ receipt and the acquisition of tenure for women in the sciences. Blickenstaff (2005, pp. 371-2) noted nine factors used to explain women's absence in STEM. 
In addition to the factors already identified above were certain biological differences between men and women; girls' lack of preparation for science studies and careers; girls' attitudes toward science; irrelevant curricula; pedagogical approaches that favor male students; a "chilly" climate towards girls and women in science; pressure on girls and women to undertake traditional gender roles; and an inherently masculine worldview in scientific epistemology.

\section{STEM CAREERS}

Careers in the STEM areas tend to follow traditional career models that favor men more than women. Based on perceptions that the ideal worker is a man, STEM work and career expectations include long hours, face time, and uninterrupted career paths (cf. Acker, 1990; Bailyn, 2003; Benschop and Brouns, 2003; Dean and Fleckenstein, 2007). O'Neil and Bilimoria (2005) have argued for the need for women's careers to be examined separately from men's careers. They suggest that there is a gap between organizational rhetoric and practice in relation to actions aimed at retaining women.

In STEM areas, women are more likely to report that they are not taken as seriously nor does their work receive the same respect as their male counterparts (Fox, 2001). Fox (2001, p. 661) has noted that "women's educational attainments do not translate into scientific career attainments, especially advancement in rank, on a par with men's". Women's lack of progress to senior roles in organizations has been attributed to glass ceilings, sticky floors, maternal walls (Shellenbarger, 2007) and concrete walls (Burke and Vinnicombe, 2005) - all barriers to women's careers. More recent metaphors have described women's labyrinth-like career pathways through organizations (Eagly and Carli, 2007) and the high risk, glass cliff leadership positions into which women are disproportionately appointed (Ryan and Haslam, 2005, 2007).

De Welde and Laursen (2011, p. 571) suggest that a more useful metaphor is that of a "glass obstacle course" as this more appropriately captures the unequal nature of the gendered processes that operate in relation to women's careers in STEM. They identify these processes as including exclusion from the "old boys club", sexism, insufficient number of women as role models and work-life balance. These barriers impact on women's choices and their satisfaction with their careers in the STEM fields in a range of ways. Faulkner (2009), for example, has noted the impact of being excluded from the old boy's network and how this can reduce women's power and influence as well as their access to 
knowledge on how work gets done and how the promotion systems operate. For De Welde and Laursen, the barriers women face are not static and can appear and reappear at any stage regardless of whether or not these challenges have already been "conquered". The authors contend that viewing women's career development as advancement through a glass obstacle course helps explain why some women advance further than others even when working under the same conditions.

\section{Pipelines}

Women's representation in senior roles has been explained in terms of pipelines. Firstly, there is a talent pipeline that women must negotiate. The talent pipeline proposes that with the right education, training and experience it is only a matter of time before women make it to senior positions in organizations (Fox, 2001). However, a recent report Pipeline's Broken Promise suggests otherwise (Carter and Silva, 2010). The talent pipeline is not as promising for women as had been expected and despite equivalent qualifications and experience women lag behind men in terms of their advancement and salary (Carter and Silva, 2010). The leaky pipeline metaphor has been used to explain women leaving organizations at various stages of career trajectory (Blickenstaff, 2005; Hewlett and Luce, 2005; Bilimoria and Liang, 2012). There are a variety of reasons that women leave organizations, some of which have been noted above. Women academics, for example, are less satisfied with academic workplaces and are more likely to leave unwelcoming cultures at earlier stages than their male counterparts (Hill et al., 2010). The usefulness of the leaky pipeline metaphor has been questioned, being seen by some as oversimplifying the reasons why women leave STEM studies and careers (e.g., Herzig, 2004; Mattis, 2007; Banning and Folkstead, 2012).

\section{OUR RESEARCH FOCUS}

As noted earlier, much of the research to date has looked at why women leave and why they appear to be less successful than their male counterparts in pursuing careers in STEM. The adequacies of the metaphors that are in use to describe women's careers generally and women in STEM in particular have been questioned. Thus it is timely to move beyond the question of "Why do they leave?" and to instead move the focus to why women stay, what organizations are doing to facilitate the career development of women in STEM areas, and challenging 
organizational discourse and practice to further encourage the recruitment, advancement and retention of women in STEM careers.

The research on women's careers in STEM presented in this edited volume can be broadly grouped into three areas, focused at the individual, organizational, and praxis levels. The first section focuses on individual perspectives relating to women's experiences and decisions to stay in or leave their STEM careers. In other words, the research presented in this section addresses why women persist in STEM careers, how they advance their STEM careers, and how they navigate caring- and family-related decisions in the context of their work and performance demands. The second section of this volume focuses on organizational initiatives and describes how such changes make a positive difference for women's careers in STEM. This research looks at how gender change projects can be designed and implemented within feminist frameworks and what this might mean for participants and gender equity, diversity and inclusion in the organization. Successful initiatives are examined and key lessons highlighted in this section. The third section, addressing praxis, focuses on the need to reframe organizational discourse and practice. Areas highlighted include critical reflection on the norms relating to what makes a successful STEM worker, how caring and family responsibilities are described and enacted, extant discourse and practice relating to gender based organizational initiatives, and the changes needed within university education so that gender becomes a visible part of STEM curricula. These themes are explained in more detail in the next section.

\section{ORGANIZATION OF THIS VOLUME}

This book presents 11 research studies about women in academic and professional occupations within STEM. There are five chapters in the first section that focus on women's experiences.

\section{Part I: Women's Individual Experiences in STEM Careers}

In Chapter 2, Kathleen Buse and Diana Bilimoria qualitatively examine factors at the individual level that differentiate women who remain or have "persisted" in engineering careers and those who have not. Interviews with 31 women with engineering qualifications and careers from the United States of America reveal differences between those who stay and those who leave in areas that include engineering identity, selfefficacy and outlook and in their interpretations of deriving meaning, 
purpose and challenge from their engineering work. Through the theoretical concepts of the ideal self and work engagement, the authors explain their observations and make suggestions for practices enhancing persistence in the careers of women in engineering.

The theme of career persistence is continued in Chapter 3. In this chapter Romila Singh, Nadya Fouad, Mary Fitzpatrick, Catia Figueiredo and Wen Hsin Chang explore the drivers behind the career choices made by women engineers. Using social cognitive career management theory and turnover theory, they establish the key differences between women who have left technical workplaces and those who remain. Factors such as perceived organizational support, workplace barriers related to undermining behavior and incivility, support from co-workers and supervisors, career satisfaction, and commitment to the engineering profession were identified as differentiating the women engineers who persisted in their careers versus those who did not.

In Chapter 4, Margaret Nowak, Melissa Marinelli, Linley Lord and Dede Bonner examine the career attitudes and motivations of women working in professional technical and scientific roles in the mining industry in Australia. Using a career anchors questionnaire supported by in-depth interviews, the authors provide insights regarding the career decisions of these women. A desire for lifestyle, constant challenge and stimulation from work, job security and stability, and a desire to build their careers are revealed as key career influences. The authors suggest that the combination of the career anchors questionnaire with a career focused discussion on key motivators may help organizations develop more appropriate and targeted retention strategies for women in science and technology careers.

The challenges of work and family responsibilities for women in STEM careers are explored in Chapter 5. In their Australian based study, authors Mary Ayre, Julie Mills and Judith Gill examine the family issues that affect women engineers and the ways they resolve these issues. Utilizing a similar approach to a larger Australian study, the Careers Review of Engineering Women (CREW), this study explores the career experiences of women from a single Australian technical university who graduated between 1974 and 2008. This group had a remarkably high retention rate and were more likely to have caring and family responsibilities. The authors found that the selection of an employer with family-friendly policies as well as joint responsibility for parenting by both parents were key contributing factors to women's decisions to remain in engineering careers.

In Chapter 6, the focus moves to the advancement of women in the engineering profession. Melissa Marinelli and Linley Lord examine the 
successful transitions of women engineers into managerial and leadership roles within the engineering profession. From interviews with Australian women engineers occupying senior roles, the authors provide insight into the nature of the roles these women have chosen to pursue as they advance their careers, and the aspects of these roles that are most important to them. The factors influencing movement to manager/leader roles are presented, revealing the combination of individual, structural, and interpersonal or relational elements vital to successful transition to senior roles.

\section{Part II: Organizational Initiatives Advancing Women in STEM Careers}

The three chapters in the second part of this book focus on organizations that employ and represent women in STEM careers and the initiatives that create change in women's workforce participation and advancement in these fields.

In Chapter 7, Charlotte Holgersson, Pia Höök and Anna Wahl describe the design and implementation of a women-only change project involving women engineers in two technical organizations in Sweden. The purpose of the project, which drew on the concept of "women as a power resource", was to engage the participants to work toward improving gender equity within their organization. Changes were realized in both organizations studied, and individuals reported increased knowledge, awareness and empowerment, and advancement of careers in many cases. Within the organizations, the creation of women's networks and the prioritization of diversity as a strategic objective were realized. The authors conclude by reflecting on the implementation of the project and share lessons learned.

The exploration of initiatives to increase the number of women in STEM careers continues in Chapter 8. Focusing on the academic sector, Diana Bilimoria and Xiangfen Liang discuss the National Science Foundation's ADVANCE program to address gender equity issues and the leaky pipeline in academic STEM in colleges and universities in the United States. Analysis of the effectiveness of a variety of initiatives broadly grouped as pipeline initiatives and cultural initiatives was undertaken. Results showed a positive change in the number of women faculty in STEM at involved universities, but that women continue to be under-represented particularly at associate professor and professor ranks. The authors conclude that a portfolio of varied and multi-targeted gender equity initiatives is most effective in achieving gender equity transformation. 
The role of institutional and representative bodies is addressed in Chapter 9. In this chapter, Erin Cadwalader, Joan Herbers and Alice Popejoy highlight the issue of gender disparity in scholarly recognition as an important influence on the attrition of women from academic STEM careers. The authors detail the development and outcomes of a particular initiative - the Advancing Ways of Awarding Recognition in Disciplinary Societies (AWARDS) project. This project was implemented by the Association for Women in Science (AWIS) with the purpose of working with scientific disciplinary societies on the elimination of gender bias from their awards selection processes. Although it is too early to know if long-lasting change has been achieved, the authors point to early successes in raising awareness of implicit bias and strategies for overcoming it.

\section{Part III: Praxis: Changing Extant Discourse and Practice about Women in STEM Careers}

The final three chapters of Part III focus on exploring and challenging the norms, discourse and practice surrounding gender and gender equity in STEM careers.

In Chapter 10, Marieke van den Brink and Lineke Stobbe examine the perceptions surrounding gender equality interventions in The Netherlands aimed at encouraging women to stay in the scientific STEM community and increasing the number of female STEM professors. Using material related to two formal equality interventions discourse analysis reveals a contradiction - termed the "getting help" dilemma - in which such programs are perceived by scientists to be both helpful and harmful to women's scientific careers. To explain this contradiction, the authors challenge the assumption that meritocracy is gender neutral and exposes the invisible privilege that male scientists enjoy. The "getting help" dilemma is proposed as an instrument for reflection and questioning of current gender equality practice.

The organizational norms relating to combining career and care responsibilities are explored in Chapter 11 by Channah Herschberg, Claartje Vinkenburg, Inge Bleijenbergh and Marloes van Engen. The authors present findings from an action research project conducted within the engineering faculty of a technical university in The Netherlands. Interviews and a focus group conducted with male and female academics reveal that whilst care issues are important for both male and female engineering academics, the recognized norm is that care is not a topic of conversation within the faculty. However, in some situations this norm is negotiated and challenged. The authors show that actively negotiating 
norms is a potential source of change and present a suite of suggestions for enacting this change within academe.

Our edited collection closes with Chapter 12 by Sally Male. In this chapter, the author proposes that the idea that "engineering is gendered" is a threshold concept. The gendered nature of engineering - or the influence of stereotypically masculine attributes - limits the effectiveness of engineering education, practice, and the inclusivity of the profession. Threshold concept theory defines threshold concepts as transformative and troublesome. The author argues that recognizing the gendered nature of engineering as a threshold concept can open new ways of thinking and understanding for engineers, but that assistance is needed in becoming comfortable with the concept. The chapter concludes with the suggestion that this threshold concept be taught to engineering students, academics and professionals, and approaches to its teaching are also recommended.

\section{CONCLUSION}

Drawing on research conducted in the United States, Australia and Europe, this volume examines the reasons for women's low participation in STEM and offers examples of successful ameliorative strategies at individual, organizational, and normative discourse and practice levels. The research presented here spans industry and academe, and focuses on the nature of STEM careers, individual career success strategies, successful organizational initiatives relating to women in STEM careers, and recommendations for praxis - changing the normative structure of extant discourse and practice. We hope that this volume will be interesting and relevant to researchers and practitioners seeking to increase women's participation and success in the STEM fields and transform organizations and institutions to better facilitate the advancement and development of women in STEM careers.

\section{REFERENCES}

Acker, J. (1990), 'Hierarchies, jobs, bodies: A theory of gendered organizations', Gender and Society, 4(2), 139-58.

Australian Academy of Science (2013), Gender Equity: Current Issues, Best Practice and New Ideas, Canberra, Australia, Australian Academy of Science, accessed December 15, 2013 from http://science.org.au/policy/documents/ GenderEquityEMCRForum.pdf.

Bailyn, L. (2003), 'Academic careers and gender equity: Lessons learned from MIT', Gender, Work, and Organizations, 10, 137-53. 
Banning, J. and J. Folkstead (2012), 'STEM education related dissertation abstracts: A bounded qualitative meta-study', Journal of Science Education and Technology, 21(6), 730-41.

Bell, S. (2009), Women in Science in Australia: Maximising Productivity, Diversity and Innovation, Canberra, Australia, accessed from http:// www.lhmartininstitute.edu.au/publications/3-prof-sharon-bell.

Benschop, Y. and M. Brouns (2003), 'Crumbling ivory towers: Academic organizing and its gender effects', Gender, Work and Organization, 10(2), 194-212.

Bilimoria, D., S. Joy and X. Liang (2008), 'Breaking barriers and creating inclusiveness: Lessons of organizational transformation to advance women faculty in academic science and engineering', Human Resource Management, 47(3), 423-41.

Bilimoria, D. and X. Liang (2012), Gender Equity in Science and Engineering: Advancing Change in Higher Education, New York: Routledge.

Blickenstaff, J.C. (2005), 'Women and science careers: Leaky pipeline or gender filter?', Gender and Education, 17(4), 369-86.

Burke, R.J. and M.C. Mattis (2007), Women and Minorities in Science, Technology, Engineering and Mathematics: Upping the Numbers, Cheltenham, UK and Northampton, MA: Edward Elgar.

Burke, R.J. and S. Vinnicombe (2005), 'Advancing women's careers', Career Development International, 10(3), 165-7.

Carter, N. and C. Silva (2010), Pipeline's Broken Promise, New York: Catalyst.

Dean, D.J., and A. Fleckenstein (2007), 'Keys to success for women in science', in R.J. Burke and M.C. Mattis (eds), Women and Minorities in Science, Technology, Engineering and Mathematics, Cheltenham, UK and Northampton, MA: Edward Elgar, pp. 28-46.

De Welde, K. and S. Laursen (2011), 'The glass obstacle course: Informal and formal barriers for women Ph.D. students in STEM Fields', International Journal of Gender Science and Technology, 3(3), 571-95.

Eagly, A.H. and L.L. Carli (2007), 'Women and the Labyrinth of Leadership', Harvard Business Review, 85(9), 63-71.

European Parliament (2008), 'European Parliament resolution of 21 May 2008 on women and science', accessed December 15, 2013 from http://www. europarl.europa.eu $/$ sides $/$ getDoc.do?type $=$ TA\&language $=$ EN\&reference $=$ P6TA-2008-0221.

Faulkner, W. (2009), 'Doing gender in engineering workplace cultures: I. Observations from the field', Engineering Studies, 1(1), 3-18.

Fouad, N., M. Fitzpatrick and J. Liu (2011), 'Persistence of women in engineering careers: A qualitative study of current and former female engineers', Journal of Women and Minorities in Science and Engineering, 17(1), 69-96.

Fouad, N. and R. Singh (2011), Stemming the Tide: Why Women Leave Engineering, accessed December 15, 2013 from http://studyofwork.com/files/ 2011/03/NSF_Women-Full-Report-0314.pdf.

Fox, M. (2001), 'Women, science and academia: Graduate education and careers', Gender and Society, 15(5), 654-66.

genSet (2010), Recommendations for Action on the Gender Dimension in Science, Science in Society Programme of the European Commission, 
accessed December 15, 2013 from http:/www.google.com/url?sa=t\&rct= $\mathrm{j} \& \mathrm{q}=\&$ esrc $=\mathrm{s} \& \mathrm{frm}=1 \&$ source $=$ web $\& \mathrm{~cd}=1 \& \mathrm{ved}=0 \mathrm{CCwQFjAA} \& u r \mathrm{u}=\mathrm{http} \% 3 \mathrm{~A}$ $\% 2 \mathrm{~F} \% 2 \mathrm{~F} w w w . g e n d e r i n s c i e n c e . o r g \% 2 F i n d e x . p h p \% 2 F d o w n l o a d s \% 2 F d o c \_d o w n$ load $\% 2 \mathrm{~F} 18$-genset-consensus-report-recommendations-for-action-on-the-genderdimension-in-science\&ei=ZAevUtPZA4ngqQHrvICwBQ\&usg=AFQjCNFqpv1e 1tMSAWuEBG_sYgbt0rNnlg\&sig2=BuMkTCB0zhz0bI2wKpRMlA\&bvm=bv. 57967247,d.aWM.

Goulden, M., K. Frasch and M.A. Mason (2009), Staying Competitive: Patching America's Leaky Pipeline in the Sciences, accessed December 15, 2013 from http://www.americanprogress.org/issues/2009/11/women_and_sciences.html.

Herzig, A.H. (2004), 'Becoming mathematicians: Women and students of color choosing and leaving doctoral mathematics', Review of Educational Research, 74(2), 171-214.

Hewlett, S. and C. Luce (2005), 'Off-ramps and on-ramps: Keeping talented women on the road to success', Harvard Business Review, 83(3), 43-54.

Hewlett, S., C.B. Luce, L.J. Servon, L. Sherbin, P. Shiller and E. Sosnovich (2008), The Athena Factor: Reversing the Brain Drain in Science, Engineering and Technology, Boston, MA: Harvard Business Review.

Hill, C., C. Corbett and A.S. Rose (2010), Why So Few? Women in Science, Technology, Engineering and Mathematics, Washington, DC, USA, AAUW, acessed December 15, 2013 from http://www.aauw.org/research/why-so-few/.

Long, J.S. (ed.) (2001), Scarcity to Visibility: Gender Differences in the Careers of Doctoral Scientists and Engineers, Washington, DC: National Academies Press.

Mattis, M.C. (2007), 'Upstream and downstream in the engineering pipeline: What's blocking US women from pursuing engineering careers? in R.J. Burke and M.C. Mattis (eds), Women and Minorities in Science, Technology, Engineering, and Mathematics: Upping the Numbers, Cheltenham, UK and Northampton, MA: Edward Elgar, p. 334.

McIlwee, J. and J. Robinson (1992), Women in Engineering: Gender, Power and Workplace Culture, Albany, NY: State University of New York Press.

Mills, J., M. Ayre and J. Gill (2010), Gender Inclusive Engineering Education, New York: Routledge.

Mills, J., V. Mehrtens, E. Smith and V. Adams (2008), CREW Revisited in 2007: The Year of Women in Engineering:- An Update on Women's Progress in the Australian Engineering Workforce, Barton, Engineers Australia, acessed December 15, 2013 from http://www.engineersaustralia.org.au/shadomx/apps/ fms/fmsdownload.cfm?file_uuid=7DA323DA-E3CC-A6FB-8DB3-4D97EFFB BEEF\&siteName=ieaust.

National Academies (2007), Rising Above the Gathering Storm: Energizing and Employing America for a Brighter Economic Future, Washington, DC: National Academies Press.

National Research Council (2007), Beyond Bias and Barriers: Fulfilling the Potential of Women in Academic Science and Engineering, Washington, DC: National Academies Press.

National Science Foundation (2010), 'Science and Engineering Indicators 2010', accessed December 15, 2013 from www.nsf.gov/statistics/seind10/start.htm. 
O’Neil, D.A. and D. Bilimoria (2005), 'Women's career development phases: Idealism, endurance and reinvention', Career Development International, 10(3), 168-9.

Ryan, M.K. and S.A. Haslam (2005), 'The glass cliff: Evidence that women are over-represented in precarious leadership positions', British Journal of Management, 16, 81-90.

Ryan, M.K. and S.A. Haslam (2007), 'The glass cliff: Exploring the dynamics surrounding the appointment of women to precarious leadership positions', Academy of Management Review, 32(2), 549-72.

Shellenbarger, S. (2007), 'Government eases path for parents to sue employers', Wall Street Journal Online.

Valian, V. (1998), Why So Slow: The Advancement of Women, Cambridge, MA: MIT Press. 